\title{
Estructura sintáctica y esquemas entonativos en enunciados interrogativos absolutos del español hablado en Cuba
}

\author{
Dania Ramos-Martín
}

* M.Sc. en Lingüística Aplicada. Docente de Español, Facultad de Lenguas Extranjeras, Universidad de La Habana, Cuba.

Correo electrónico:

daniarm@rect.uh.cu

Recibido: 24 de julio del 2013

Aprobado: 20 de septiembre del 2013

Cómo citar este artículo: Ramos-Martín, Dania. "Estructura sintáctica y esquemas entonativos en enunciados interrogativos absolutos del español hablado en Cuba". Rastros Rostros 15.29 (2013): 59-72. Impreso.

\begin{abstract}
Resumen
El trabajo es parte de un estudio sobre la inversión léxico-sintáctica en la oración interrogativa absoluta en el español cubano y sus esquemas entonativos más frecuentes. Partiendo de resultados anteriores que comprueban la tendencia de los hablantes a mantener el orden lineal de los elementos oracionales, pretendemos determinar los valores comunicativos que adoptan estos enunciados en el discurso (coloquial), a partir de la interacción interniveles y las condiciones pragmáticas de su uso. El estudio de la muestra -de tipo descriptivo-explicativo- arrojó que el enunciado interrogativo que se realiza mediante el entonema 3 (E3) puede tener varias funciones semántico-pragmáticas.
\end{abstract}

Palabras clave: análisis del discurso, entonación, enunciado interrogativo absoluto, sintaxis.

Syntactic Structure and Intonation Patterns in Absolute Interrogatives in Spoken Spanish in Cuba

\begin{abstract}
This article is part of a study into lexical-syntactic inversion in absolute interrogative sentences in Cuban Spanish and their most common intonation patterns. As a starting point, the article uses previous results that confirm speakers' tendency to maintain the linear order of sentence parts, and seeks to determine the communicative value that these expressions take on in discourse (colloquial), based on inter-level interaction and pragmatic conditions of use. A study of the sample (descriptive-explanatory type) found that interrogative expressions using intonation 3 (E3) can have various semantic-pragmatic uses.
\end{abstract}

Keywords: discourse analysis, intonation, absolute interrogative expression, syntax.

Estrutura sintática e esquemas de entonação em enunciados interrogativos absolutos no espanhol falado em Cuba

Resumo

Este trabalho é parte de um estudo sobre a inversão léxico-sintática da oração interrogativa absoluta no espanhol cubano e seus esquemas de entonação mais frequentes. Partindo de resultados anteriores que comprovam a tendência dos falantes de manter a ordem linear dos elementos oracionais, pretendemos determinar os valores comunicativos que adotam esses enunciados no discurso (coloquial), a partir da interação de interníveis e as condições pragmáticas de seu uso, o estudo da mostra — do tipo descritivo-explicativo- apontou que o enunciado interrogativo mediante o entonema 3 (E3) pode ter várias funções semântico-pragmáticas.

Palavras-chave: análise do discurso, entonação, enunciado interrogativo absoluto, sintaxe. 


\section{Introducción}

En Cuba se llevan a cabo desde hace más de dos decenios estudios sobre la interrogación. Las investigaciones lideradas por la entonóloga García Riverón ${ }^{1}$ han tenido entre sus principales resultados la descripción tipológica de las oraciones interrogativas-inquisitivas ${ }^{2}$ y del subsistema entonativo a él asociado. Teniendo en cuenta que gran parte de la literatura sobre el tema utiliza enfoques reduccionistas, al estudiar el fenómeno solo en su dimensión gramatical o física (acústica), obviando las interacciones entre niveles, contextuales y con medios de expresión extralingüísticos, nos hemos propuesto investigar sobre la relación entre estructura sintáctica y entonación en enunciados interrogativos absolutos y cómo se manifiesta esta relación en el coloquio, siguiendo el enfoque comunicativo, propugnado por García Riverón.

\section{Referentes teóricos}

La gran mayoría de las gramáticas en lengua española ${ }^{3}$ postulan que la oración interrogativa absoluta ${ }^{4}$ se caracteriza desde el punto de vista de su estructura sintáctica por la anteposición del verbo al resto de los elementos oracionales, aun cuando se deja claro que la entonación

1 Véanse La interrogación y aspectos de la entonación hispánica. Metodología I, Aspectos de la entonación hispánica. Análisis acústico de las muestras del español de Cuba II, Aspectos de la entonación hispánica. Las funciones de la entonación en el español de Cuba III, de la autora.

2 En ellas el emisor tiene como objetivo fundamental hallar un elemento desconocido: despejar una incógnita en una situación comunicativa dada.

3 Se revisaron las siguientes obras: Gramática de la Lengua Castellana (s.a.), de Vicente Salvá y Pérez; La oración y sus partes, de Rodolfo Lenz; Gramática castellana destinada al uso de los americanos de Andrés Bello; Curso superior de sintaxis de Samuel Gili Gaya; Manual de entonación española de Tomás Navarro Tomás; Gramática funcional del español de César Hernández Alonso; Esbozo de una nueva gramática de la lengua española de la Real Academia Española; Gramática descriptiva del español de Ignacio Bosque y Violeta Demonte y Nueva Gramática de la Lengua Española de la Real Academia Española.

4 Las gramáticas normativas coinciden en separar -aunque con algunas variaciones en la nomenclatura- dos grupos de oraciones interrogativas: las parciales y las totales. En las primeras la incógnita queda restringida a un elemento oracional, normalmente un pronombre o adverbio interrogativo; en las segundas al carácter afirmativo o negativo de la predicación. La marca acústica de estas últimas es la curva ascendente, para la variante peninsular y circunfleja para las lenguas del Caribe. Raquel García Riverón en La interrogación estableció que las oraciones interrogativas absolutas o totales se caracterizan porque el emisor desconoce, en alto grado, la incógnita. Esta última puede estar estructurada por un par antonímico (sí/no) o por una serie de elementos con relaciones paradigmáticas de tipo temático. puede ser marca suficiente para distinguir un enunciado interrogativo de este tipo de la enunciativa correspondiente. Asimismo, las obras normativas con las que cuentan nuestros estudiantes de español como lengua extranjera (casi todas editadas en España), refieren que el esquema entonativo característico para la oración interrogativa absoluta es el de final ascendente, a tono con las descripciones hechas para el español en su variante peninsular por autores como Navarro y Quilis.

La Gramática descriptiva de la lengua española, obra medular en el panorama reciente de la investigación lingüística en el hispanismo -en tanto que contiene un análisis semántico-pragmático del enunciado interrogativo español del que adolecen las gramáticas anteriores-, estipula que el orden verbo-sujeto "constituye un medio gramatical para forzar la interpretación remática de la proposición (es decir, la interpretación en la que todo el contenido proposicional se interpreta como información nueva o en primer plano)" (Escandell 3935).

Por otra parte, se establece que cualquier variación tanto en la estructura sintáctica como en la curva entonativa ${ }^{5}$ tiene implicaciones para la interpretación de este tipo de enunciados. Así, se afirma que ni las estructuras con y sin inversión son intercambiables en todos los contextos, ni las propiedades sintácticas de unas y otras son totalmente coincidentes. De este modo, se establece el orden verbo/sujeto como el no marcado, ante la necesidad de convertir la estructura oracional en un 'juicio tético’: ¿Ha decidido ya Juan cuándo va a convocar la reunión?, ¿Conoce tu marido a alguien del tribunal? Por el contrario, el orden sujeto/verbo se asocia con estructuras bimembres que presentan un sujeto temático o presupuesto y un predicado remático o focal. "Esta organización informativa, que asevera la relación entre sujeto y predicado, es por definición incompatible con la modalidad interrogativa, que se caracteriza precisamente por dejar en suspenso el signo correspondiente a dicha relación" (3952).

La presencia de oraciones interrogativas sin inversión se justifica, según esta obra, solo en contextos en los que el enunciado es atribuido a otros, ${ }^{6} \mathrm{o}$ sea, existe una proposición declarativa previa, con contenido pre-

\footnotetext{
5 En la obra se estima que el patrón no marcado para las interrogativas que nos ocupan es el determinado por la interacción de la estructura léxico gramatical con una curva de final ascendente.

6 La Nueva Gramática de la Lengua Española refiere un uso semejante de la no inversión, cuando alude a los enunciados que "pretenden confirmar o poner en duda alguna afirmación previa, especialmente si esta se ha presentado con sujeto antepuesto" (Real Academia Española 3155).
} 
supuesto. Por tanto, se asevera, sin elementos demostrativos, que están "asociadas sistemáticamente al patrón entonativo circunflejo, precisamente aquel que indica el carácter atribuido de las representaciones" (3954).

En cuanto a las investigaciones sobre el español de América, hay apenas referencias al tema que nos ocupa. Sosa hace mención al fenómeno de manera muy superficial en La entonación del español. Afirma que en Hispanoamérica "se pueden dar casos de inversión sujeto-verbo, si bien estos son sumamente marginales en la lengua no literaria o afectada. Este uso parece ser más frecuente en el español peninsular" (149). El autor describe un esquema entonativo circunflejo para el ámbito caribeño: ocurre un descenso a partir de la última sílaba tónica del enunciado.

Con respecto a la variante cubana del español, García Riverón (336) en La actualización de la incógnita en las interrogativas rusas y españolas, reconoce que la posición inicial del verbo:

puede acentuar su valor comunicativo como elemento desconocido, a la vez que limita las posibilidades comunicativas de otros miembros de la oración que no pueden actuar, entonces, en calidad de incógnita. Sin embargo, esta forma de concretar el verbo incógnita de la oración tiene un carácter facultativo debido a que, según demuestran nuestro fichero y fonoteca, obedece a diferencias de estilo o a diferencias regionales dentro del sistema de la lengua.

La autora concluye en su artículo que en español abundan estructuras en las que es posible actualizar varias incógnitas:

El rasgo tipológico fundamental de nuestra lengua es la no expresión formal de la actualización de la incógnita [...] En el sistema comunicativo del español, la expresión de la incógnita queda implícita, no se concreta por medios lingüísticos (formales), aunque el oyente puede deslindarla. En el proceso de percepción de la pregunta se eleva el papel de la situación y el contexto, para ser más exactos, pasa a primer plano desde el punto de vista comunicativo la función que desempeñan los conocimientos que han adquirido los hablantes con anterioridad a la emisión del enunciado: la presuposición. (337)

Por otra parte, un estudio ${ }^{7}$ anterior llevado a cabo por la autora del presente trabajo de encuestas aplicadas

7 La investigación realizada fue de carácter descriptivo y utilizó el análisis cuantitativo de encuestas aplicadas a hablantes españoles y cubanos, a hablantes cubanos y españoles arrojó que, efectivamente, los hablantes de la variante cubana de la lengua española no hacen uso mayoritario de la inversión interrogativa cuando realizan el acto de preguntar. Por tanto, el orden no marcado es el de sujeto-verbo, aunque la tendencia a mantener el orden lineal de los elementos oracionales es menos acusada que la que existe entre los españoles a invertir la estructura léxico-gramatical.

De igual modo, el análisis acústico mostró que no existe una variación de la curva entonativa en enunciados con y sin inversión interrogativa en ninguna de las dos variantes de lengua abordadas. Estos resultados contradicen las gramáticas al uso, que postulan que la inversión de la estructura léxico-sintáctica acarrea un cambio también en el suprasegmento entonativo.

\section{El acto de habla interaccional}

Queremos referirnos a un término que utilizaremos cuando presentemos los resultados de la investigación: el acto de habla interaccional.

Este término ha sido perfilado por la entonóloga cubana García Riverón (Aspectos) quien ha añadido un matiz al concepto acto de habla, definido por Austin y Searle, tradicionalmente utilizado en los estudios lingüísticos.

La autora propone hablar del acto de habla interaccional (AHI) "como un signo complejo que comporta la coacción de los medios de expresión léxicos, gramaticales, prosódicos y kinésicos en el discurso oral" (Aspectos III 77). Estos AHI son, según la autora, perfectamente sistematizables, al repetirse con cierta estabilidad en determinadas situaciones comunicativas, por lo que pueden poseer significados convencionales. Este concepto es vital de cara al análisis integrador que proponemos, al concebir el hecho lingüístico sin reduccionismos que limiten la determinación de su valor comunicativo.

\section{Metodología}

El presente estudio es del tipo descriptivo-explicativo, pues pretende profundizar en el comportamiento discursivo de los enunciados interrogativos absolutos en

así como el análisis acústico de grabaciones de laboratorio de enunciados interrogativos absolutos, con el objetivo de estudiar la ocurrencia del fenómeno de la inversión sintáctica y la relación sintaxis-entorno melódico en este tipo de enunciados. Los resultados de la investigación permanecen aún inéditos. 
muestras de habla coloquial, con el fin de comprobar o refutar los presupuestos expuestos -sobre todo- por las gramáticas normativas, utilizando el enfoque comunicativo, que permite abordar el objeto de estudio con mayor complejidad.

Este enfoque comunicativo, con evidentes lazos con el análisis del discurso y la pragmática, tiene sus pilares fundamentales en la lingüística rusa y ha sido utilizado para el estudio de la prosodia en la variante cubana del español con excelentes resultados. A la luz de este enfoque, el acto de habla se analiza teniendo en cuenta elementos de la realidad lingüística y extralingüística que condicionan su empleo. Es decir, no solo se valora el contenido semántico del enunciado en cuestión, sino que se tienen en cuenta la situación comunicativa, el contexto lingüístico o discursivo y las necesidades comunicativas del emisor. Con ello se obtiene un resultado acorde con la realidad comunicativa, en la que todo hecho lingüístico tiene una existencia concreta.

Así, siguiendo este enfoque, el análisis debe tener en cuenta "los diferentes factores que intervienen en el funcionamiento de la cadena hablada: la prosodia en general, la morfosintaxis, el léxico, la gestualidad, la pragmática y la semántica, es decir, el significado que emerge del sistema y los sentidos de su uso discursivo" (citado en Bermúdez 28).

\section{Métodos y técnicas}

La investigación constó de varias etapas, que permitieron desarrollar las tareas de investigación requeridas para abordar el objeto de estudio en toda su complejidad.

Primeramente, se utilizó el método de la observación, fundamental para monitorear el comportamiento discursivo (sobre todo en el habla cotidiana) del fenómeno abordado en la investigación.

Los fragmentos auditivos aislados del material audiovisual se sometieron a un análisis acústico, mediante el cual se recopilaron los valores de frecuencia del tono fundamental ${ }^{8}$ (F0) de los contornos melódicos ${ }^{9}$ obtenidos.

8 "Resultado del número de vibraciones completas de las cuerdas vocales por unidad de tiempo" (Quilis 42). Único parámetro físico tenido en cuenta para la indagación, dado el consabido valor que tiene para el reconocimiento de las curvas entonativas en el sistema. Muchos autores, entre ellos la entonóloga cubana Raquel García Riverón, estiman que para un estudio completo de la entonación es necesario tener en cuenta los valores de intensidad, duración y timbre.

9 Melodía: contrapartida fonética de la entonación, concepto que debe relegarse únicamente a la fonología. La melodía consiste únicamente en la curva que describe la frecuencia fundamental (Martínez 111).
Este análisis se realizó con el software de origen holandés Praat, creado para estos fines; los valores obtenidos fueron procesados con el programa Microsoft Excel.

Por último, el análisis cualitativo de la muestra audiovisual utilizada nos permitió estudiar los enunciados en su realización discursiva, tomando en cuenta aspectos pragmáticos como el contexto lingüístico, la situación comunicativa en la que fue emitido el enunciado y la posible influencia de factores extralingüísticos.

\section{Características de la muestra}

La muestra está integrada por las interrogativas absolutas contenidas en el dramatizado "En la otra acera", de 57 minutos de duración, producido por la televisión cubana y estrenado en el 2010. Se seleccionó este material audiovisual porque contiene un gran número de situaciones comunicativas en las que los personajes interactúan por medio de actos de habla interrogativos.

El tópico abordado en el audiovisual es la prostitución y sus consecuencias morales. En la trama se intercalan subtópicos relacionados con el tópico central, como la comunicación intergeneracional, los gustos y las preferencias de los jóvenes, el machismo (y en contraste, el rol social de la mujer), el amor y el valor del trabajo honesto.

Teniendo en cuenta que en Cuba no existen programas televisivos del tipo reality shows, que potencian un intercambio lingüístico más libre y espontáneo, acudimos a la selección de un teleplay que aborda un tema de actualidad, con lo cual se "simulan" situaciones cotidianas, cercanas a la realidad discursiva del coloquio. ${ }^{10}$ Así, los enunciados objeto de investigación -los formalmente interrogativos (que en el discurso pueden tener alto, bajo o nulo grado de desconocimiento de la incógnita) - son abundantes. Todas las grabaciones fueron transcritas al sistema ortográfico, para facilitar el análisis auditivo y discursivo. En total, se trabajó con 42 enunciados, discriminados teniendo en cuenta

\footnotetext{
10 Van Dijk (Texto 257) define el coloquio como "una unidad de interacción social compuesta por una serie ordenada de acciones lingüísticas definida en relación con un contexto social" (257) y García Riverón establece entre sus características distintivas la inmediatez, la estricta actualización y la improvisación (Aspectos III 108). Este último rasgo desaparece en nuestra muestra, pues el intercambio lingüístico ha sido mediado por el uso previo de un guion. Sin embargo, la propia naturaleza de este tipo de producto comunicativo, que busca remedar las condiciones del discurso natural para hacerlo creíble ante la audiencia, hace que se intente preservar en el audiovisual el carácter dinámico del coloquio.
} 
las características estructurales requeridas (ausencia de pronombre interrogativo y corrección gramatical).

\section{Resultados}

Discriminamos en la muestra un total de 42 enunciados interrogativos absolutos. De ellos, 24 (57,14\%) tienen sujeto expreso; 20 (el 83,3\%) están constituidos por el pronombre de segunda persona del singular (tú). En todos los casos el sujeto está antepuesto al verbo. Aunque de manera marginal, se encontró en la muestra evidencias de la presencia del pronombre con valor enfático, hecho frecuente en el coloquio. Sin embargo, prima la tendencia a usar este pronombre con valor o bien especificativo, o bien, redundante, como indican los siguientes ejemplos:

\section{A: ¿Tú viste cómo me miraba tu mamá? \\ B: Ahora te metes en la casa y que no te vean ni por la ventana. \\ 2. A: ¿Tú no tienes una llave ocho por ahí? \\ B: Yo tengo unas llaves ahí, deja ver...}

\section{Interrogativas propiamente inquisitivas o neutras}

En cuanto a las funciones comunicativas de los enunciados discriminados, se encontró que, como se ha afirmado en abundante literatura, estos actos de habla son emitidos en situaciones comunicativas en las que el emisor demanda una información. ${ }^{11}$ La incógnita contenida en la pregunta está formada por un par de antónimos o una serie temática de elementos que el emisor desconoce en alto grado. Como ha quedado establecido para el español hablado en Cuba (García Riverón Aspectos I, Aspectos II, Aspectos III), estas estructuras sintácticas interactúan con el entonema ${ }^{12}$
3 (E3). Este entonema es hallado en interrogativas con un alto grado de desconocimiento (preguntas absolutas) cuya estructura léxico-gramatical no posee pronombre o adverbio interrogativo (Aspectos II 88). Tiene un segmento pretónico en el que la frecuencia fundamental comienza a ascender a partir de la primera sílaba del enunciado y se mantiene en suspensión o en relativa inmovilidad en el cuerpo del enunciado para continuar ascendiendo, generalmente a partir del intervalo intersilábico anterior a la última vocal tónica. En la última sílaba acentuada ocurre un descenso brusco de la F0, que continúa en el segmento postónico (Aspectos II 89).

Veamos dos ejemplos:

C: ${ }^{13}$ Muchacho, ven acá un momentico... ¿tú conoces algún mecánico por aquí?

Es que no sé lo que le pasa al

carro y el que me atiende no aparece.

B: Yo sé de mecánica.

C: Te estoy aburriendo... ¿Quieres irte ya?

B: No, yo no estoy apurado.

11 Searle clasificó estos actos de habla como directivos: aquellos en los que el hablante intenta que el oyente haga algo. El contenido proposicional es siempre que el oyente lleve a cabo alguna futura acción. Los enunciados interrogativos que mantienen en el discurso su valor inquisitivo son actos de habla directivos por excelencia.

12 García Riverón (Aspectos I, Aspectos II, Aspectos III) recoge una descripción del suprasegmento entonativo en el sistema cubano. La autora establece un inventario de oposiciones con las curvas discretizadas, obtenidas en situaciones comunicativas reales. La conmutación de las curvas entonativas en estructuras léxico-gramaticales primero similares y luego diferentes, arroja diferencias incompatibles y compatibles que sirven de sostén para deslindar los entonemas y variantes de entonema, respectivamente. Así, el español hablado en Cuba cuenta con siete entonemas y ocho variantes de entonema.

13 Se designó cada personaje con una letra del alfabeto, según su orden de aparición en el dramatizado. 


\section{Realizaciones y matices}

Encontramos en la muestra una interrogativa típicamente inquisitiva cuya curva entonativa constituye una realización del E3. Es el caso de ¿Tú sabes por aquí dónde vive Patricia?, que tiene como característica distintiva el alargamiento de la vocal $e$ en la segunda sílaba de la palabra vive. Ello le otorga al enunciado un matiz de dubitación. Este valor semántico-pragmático está dado por el incremento del tiempo vocálico y la si- tuación comunicativa que rodea el acto de enunciación justifica su uso. El emisor se encuentra buscando una dirección en un barrio que le es ajeno y está tratando de orientarse en el espacio en el momento mismo que formula la pregunta. La figura 1 muestra el comportamiento del tiempo en el enunciado. La línea uniforme representa la media, de 0,1 segundo, en tanto la línea discontinua muestra el incremento ya mencionado en la segunda sílaba de la palabra vive (0,442 s).

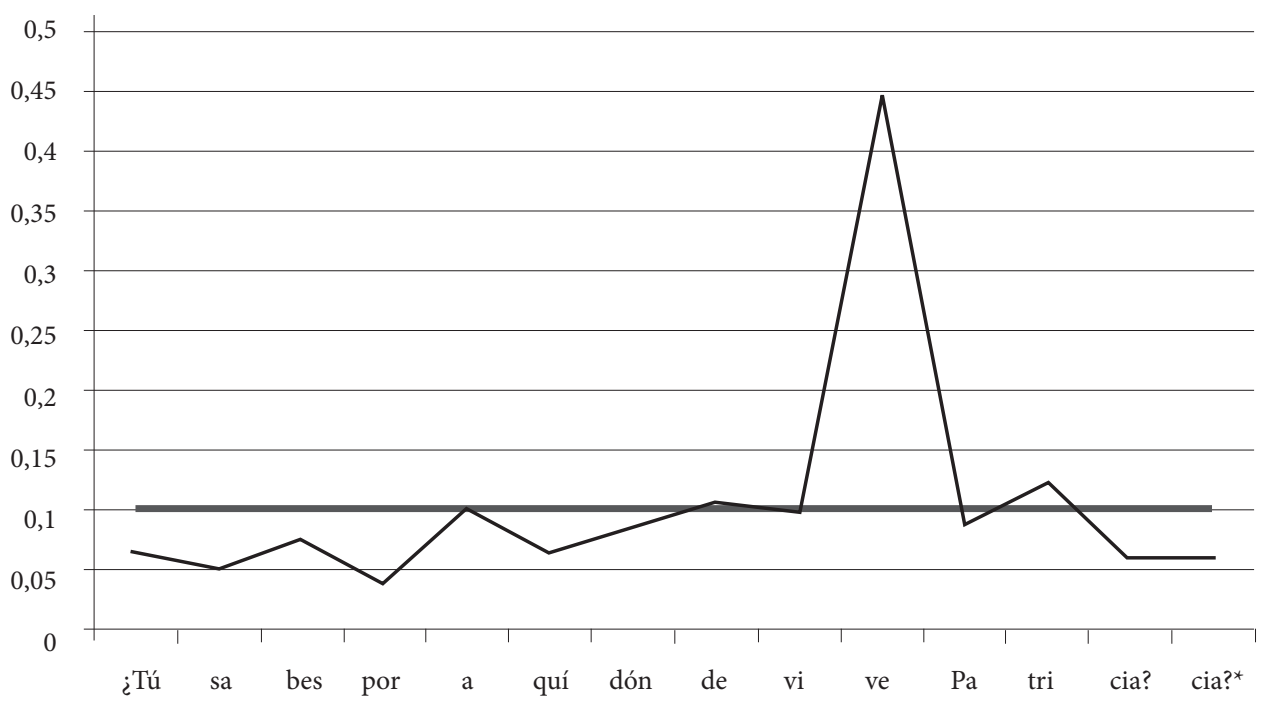

Figura 1. Comportamiento del tiempo vocálico (en segundos) del enunciado ¿Tú sabes por aquí dónde vive Patricia? El asterisco indica que se midieron dos valores dentro de la misma sílaba, uno para cada vocal Fuente. Elaboración propia.

\section{Algunos rasgos semántico-pragmáticos encontrados en la muestra}

\section{Interrogativas con valor de enunciación}

El emisor no usa algunas de las estructuras encontradas, formalmente interrogativas, con el fin de despejar una incógnita, por lo que el grado de desconocimiento con respecto a esta última es bajo. En estos AHI actúan los entonemas E3 y la variante de entonema $3 \mathrm{~b}$ (VE3b). Esta variante se utiliza en enunciados en los que el hablante quiere corroborar algo, muy cercanos a la enunciación por su bajo grado de desconocimiento de la incógnita. La frecuencia fundamental posee un movimiento escaso en el segmento pretónico. En ocasiones puede ocurrir un descenso, relacionado con el grado de "afectividad" que el hablante quiera expresar en la situación comunicativa. En la sílaba anterior a la tónica se observa un ascenso del fundamental hasta, seguido de un brusco descenso de la vocal tónica (García Riverón, Aspectos II 97).

Desde el punto de vista perceptivo estos enunciados tienen un valor interrogativo que es solo formal y su esencia semántica solo puede deducirse del contexto del AHI. Los casos siguientes tienen un valor cercano a la aseveración.

Situación comunicativa: Yunior (B) y su madre (A) conversan acerca de la creciente preocupación del primero por vestirse bien y salir a lugares caros. 
A: Mijo, ¿tú no te das cuenta que no necesitas ropa de marca para lucir bien? que $3 \mathrm{~b}$

no es más que un cartel...

3

B: ¿Tú no te das cuenta que con lo que tengo no puedo ir a ninguna parte?

Quiero ponerme la ropa que se usa, salir a los lugares que me gustan...

Como puede observarse, la intención comunicativa de la madre es hacer reflexionar a su hijo sobre la superficialidad de lo material. Por su parte, Yunior replica con otro enunciado formalmente interrogativo, a todas luces con intenciones de afirmar. El uso del no en ambos casos orienta también la interpretación de la pregunta hacia la aseveración. Obsérvense las siguientes oposiciones de enunciados que en el contexto discursivo que nos ocupa pueden ser intercambiados sin que ocurra una variación de significado considerable:

A: Mijo, ¿tú no te das cuenta que no necesitas ropa de marca para lucir bien?/

Mijo, tú no necesitas ropa de marca para lucir bien.

B: ¿Tú no te das cuenta que con lo que tengo no puedo ir a ninguna parte?/

Con lo que tengo no puedo salir a ninguna parte.

Asimismo, puede observarse un intercambio en el uso del entonema 3 y su variante $3 \mathrm{~b}$ dentro de la misma secuencia discursiva sin que varíen las funciones semántico-pragmáticas.

La curva de entonación de la primera interrogativa muestra un descenso escalonado en el cuerpo del enunciado, muy cercano a los entonemas de aseveración enunciativa $(\mathrm{E} 1)^{14}$ descritos para la variante cubana (García Riverón, Aspectos I 30-38). Sin embargo, conserva un final circunflejo, típico de enunciados interrogativos con VE $3 \mathrm{~b}$, si bien el descenso del final no es muy pronunciado (véase la figura 2).

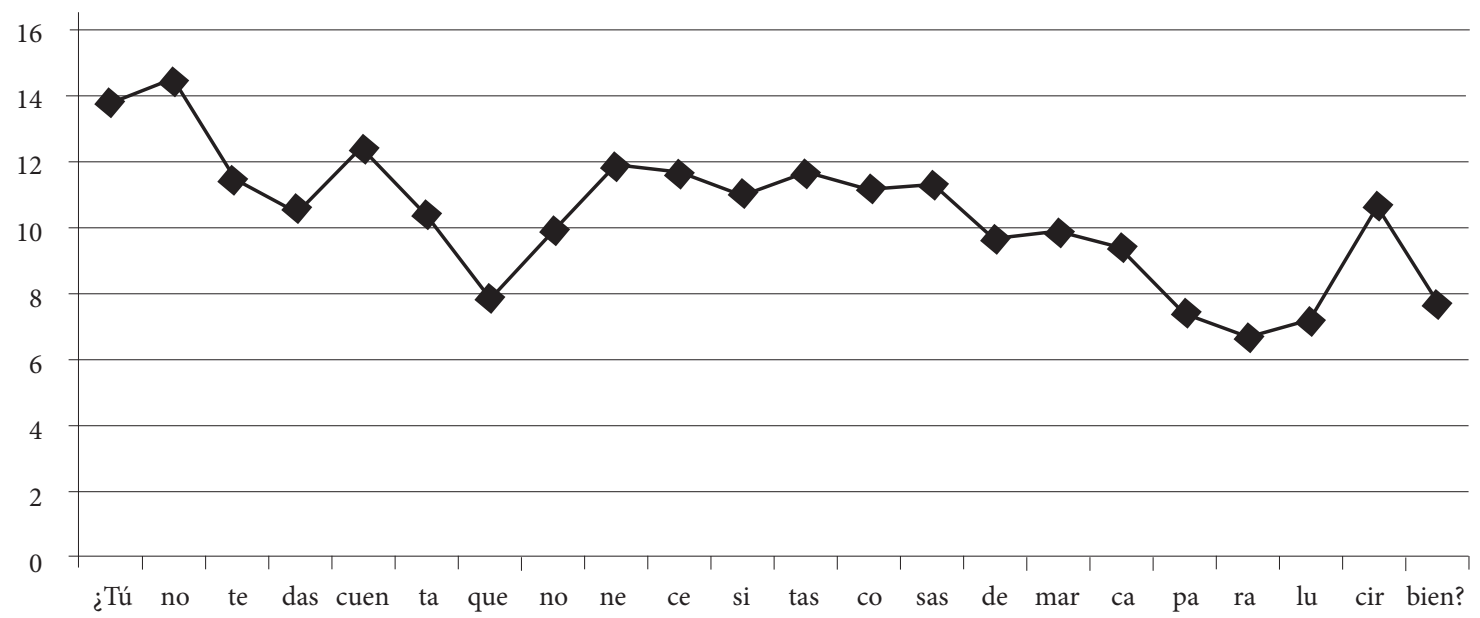

Figura 2. Recorrido de la F0 (st) del enunciado ¿Tú no te das cuenta que no necesitas cosas de marca para lucir bien? Fuente. Elaboración propia.

14 Caracterizado por un descenso escalonado en el cuerpo del tonema y un final también descendente aunque, de acuerdo con la emotividad, los indicadores acústicos pueden sufrir alguna variación. 


\section{Interrogativas con valor de reproche}

En la muestra se encontraron también estructuras interrogativas con valor de reproche..$^{15}$ En el siguiente ejemplo el emisor no lleva a cabo el acto de preguntar, sino que "protesta" por el estado de ánimo de su interlocutor y pretende provocar un cambio en su actitud. Obsérvese la secuencia:

\section{D: Mi amor, ¿qué te pasa? \\ B: Nena, no tengo ganas de hablar.}

D: ¿Tú vas a seguir con esa cara?

B: Es la misma cara de siempre, Dayana.

D: Yo tengo menos ropa que tú y no me pongo tan trágica.

Situación comunicativa: los interlocutores son novios y el muchacho ha expresado en un momento anterior su inconformidad con lo que tiene. La relación con su madre y su pareja se ha visto afectada por una modificación en su comportamiento. La respuesta de Yunior (B) en su segundo turno al hablar deja claro que la intención de Dayana (D) no es preguntar por si seguirá o no con la misma expresión en su rostro (respuesta sí/no), sino valorar negativamente su postura e impulsarlo a un cambio. Otro elemento que apoya esta inter- pretación es la entonación del enunciado, cercana a la VE3b, propia de enunciados interrogativos absolutos o formalmente interrogativos, próximos a la corroboración. La curva melódica tiene un movimiento escaso en el pretonema y un descenso pronunciado a partir de la sílaba tónica del tonema. El acto de reproche se apoya además con la gestualidad (véase figura 3 ). D aprieta la comisura de los labios, gesto que se asocia comúnmente con la inconformidad.

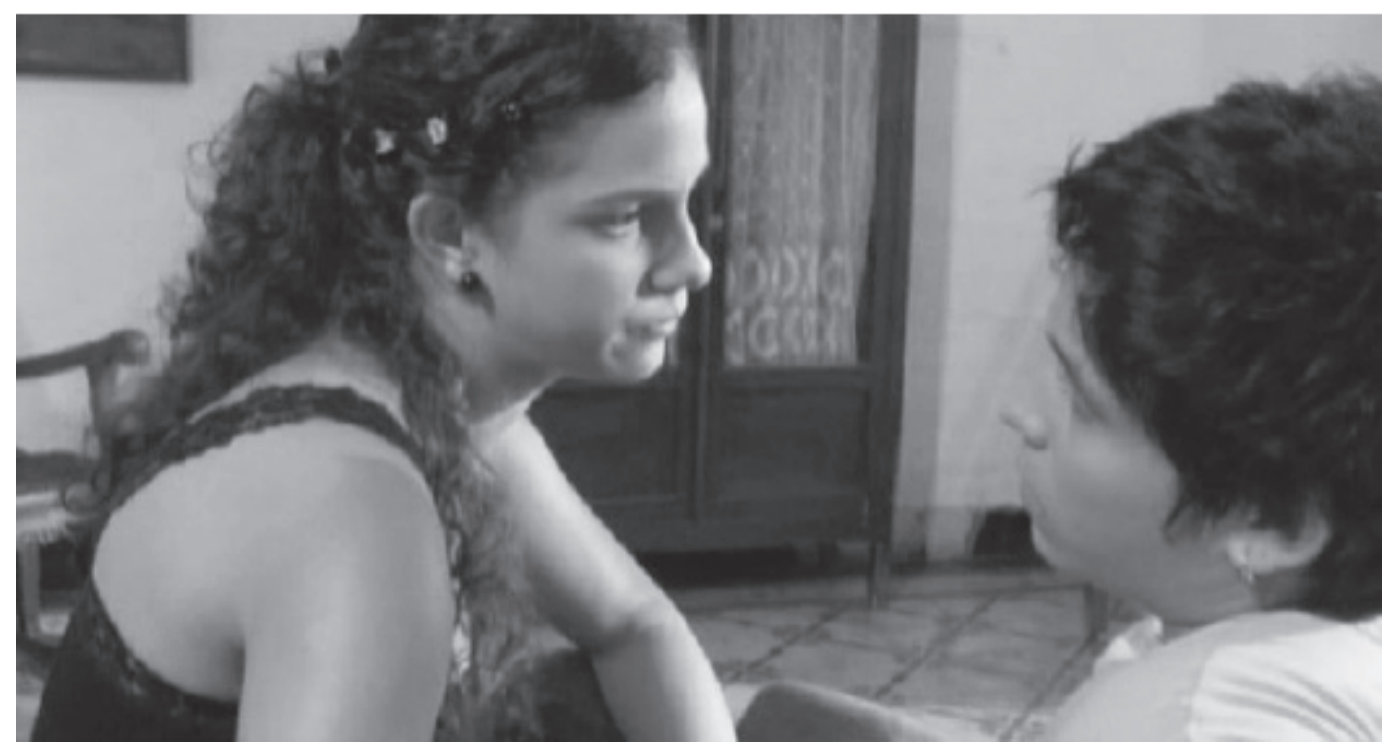

Figura 3. Fotograma que muestra el gesto que acompaña la enunciación de la interrogativa ¿Tú vas a seguir con esa cara? Fuente. Teleplay “En la otra acera”, 2010.

15 En Aspectos de la entonación hispánica III, García Riverón había citado algunos ejemplos de estos AHI, en los que el emisor valora un hecho realizado en el pasado. La autora afirma que este tipo de AHI "se diferencia de la enunciación aseverativa precisamente por el rasgo valorativo. Del mandato se distingue el reproche por la ausencia de rasgo de futuro inherente al primero y de la interrogación, porque el emisor tiene plena certidumbre o seguridad de su valoración. En consecuencia, no ha lugar hablar de un bajo grado de desconocimiento. En el reproche se valora un hecho realizado en el pasado, aunque el deseo de cambio provocado por la valoración negativa acerca a estos AHI a los mandatos" (401). 


\section{Interrogativa con valor de corroboración}

En el caso de estos enunciados formalmente interrogativos, el emisor parte de un conocimiento previo o de una presuposición, con lo cual el grado de desconocimiento de la incógnita es bajo. Con este AHI el emisor pretende verificar, dar mayor fuerza al argumento o la opinión. Obsérvense los dos enunciados siguientes, cuyas estructuras sintácticas interactúan con un E3.

\section{3}

$\mathrm{F}:$ ¿Entonces todo va bien?

B: Claro, gracias a ti que me diste la luz.

Situación comunicativa: Alfredo (F) y Yunior (B) hablan del curso de un negocio relacionado con la pros- titución. En escenas anteriores se ha visto a F sugiriéndole a B sobre lo que es más conveniente. Además, se ha visto que $\mathrm{B}$ ha puesto en práctica los consejos de $\mathrm{F}$ y ha comenzado a ganar mucho dinero. La indumentaria que exhibe permite deducir que ha habido un progreso material considerable. Por ello, la pregunta de F no tiene otro objetivo que comprobar algo que es evidente. El uso de claro en la respuesta es otro indicio de que se ha formulado la interrogativa a partir de una suposición que pretende confirmarse.

En ocasiones, la curva de entonación contiene un tono más bajo. Este uso del E3 en interacción con una estructura léxico-gramatical que incluye una referencia explícita a lo que se pregunta (en el siguiente ejemplo, estás seguro o no) orienta la interpretación hacia una comprobación de lo enunciado:

D: ¿Estás seguro que no te vas a meter en problemas?

B: Te vengo a regalar el mejor día de tu vida y tú con esa bobería...

La secuencia se produce luego de que se ha visto que Dayana (D) y Yunior (B) han discutido sobre el modo como B está ganando dinero (mediante la prostitución). En ese sentido, puede esperarse que D quiera comprobar que la salida a un lugar caro no implicará un riesgo para el buen término de la invitación.
A diferencia de las canónicas, la curva entonativa del ejemplo muestra un final circunflejo muy poco marcado, y la frecuencia del enunciado se mueve en el intervalo de los 9 a los 12 semitonos, o sea, solo de 3 semitonos. El descenso progresivo y escalonado del tono y la situación comunicativa hacen que la enunciación tenga un matiz afirmativo (figura 4).

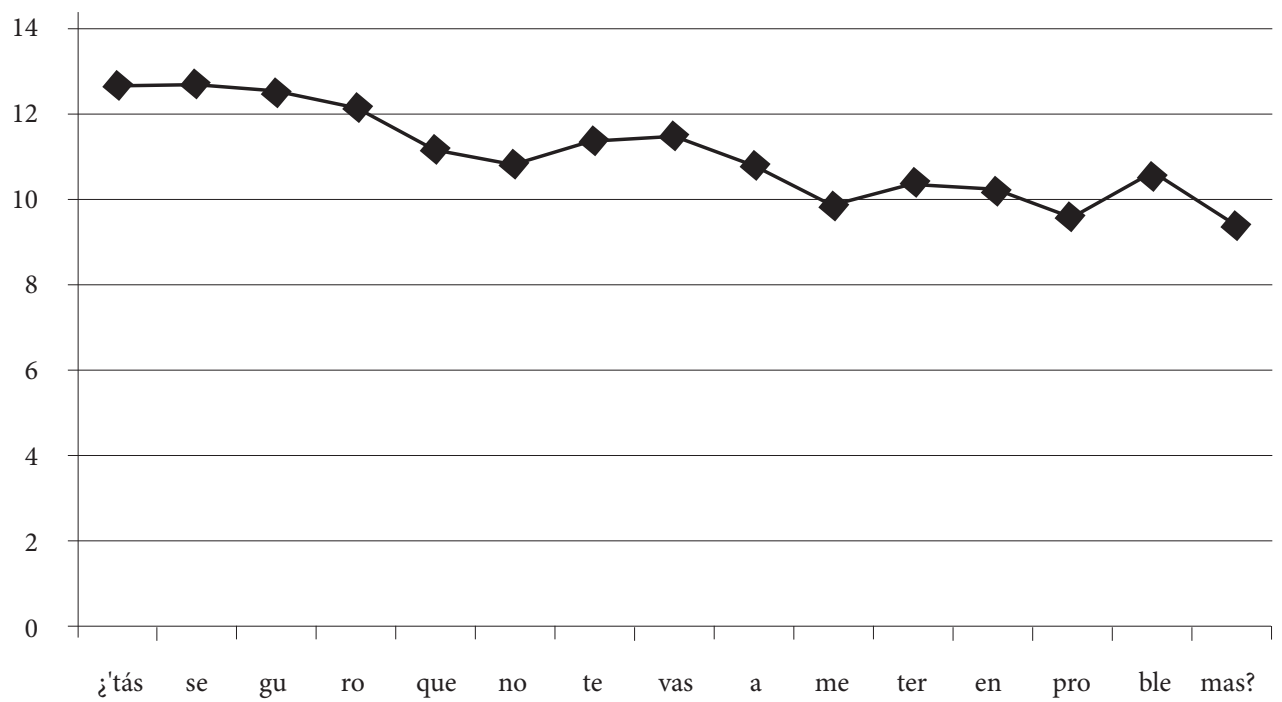

Figura 4. Recorrido de la F0 (st) del enunciado ¿Estás seguro que no te vas a meter en problemas? Fuente. Elaboración propia. 
Algo similar ocurre con el ejemplo siguiente (Figura 5), también de un AHI en el que se emite una interrogativa de corroboración a partir de un conocimiento previo, explícito en la propia enunciación. El movimiento descendente del tono en el cuerpo del entonema hace que se acerque bastante a la aseveración, y el tonema conserva los rasgos interrogativos, a saber, el final circunflejo, poco marcado. Veamos la secuencia:

B: Estamos sin dinero.

D: No pienses en ese bache, tú no puedes ser la nota discordante. Además, ¿tú no me 3

has explicado que todas las muchachas que te ha traído Alfredo tienen dinero? Ahorita salimos de eso...

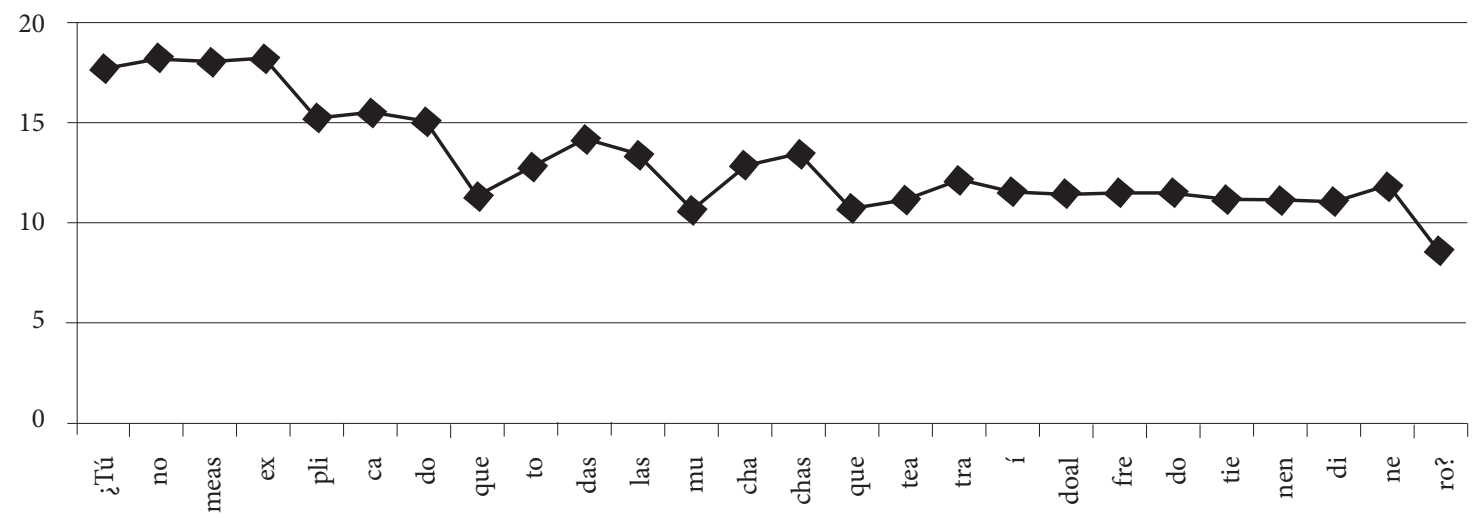

Figura 5. Recorrido de la F0 (st) del enunciado ¿Tú no me has dicho que todas las muchachas que te ha traído Alfredo tienen dinero? Fuente. Elaboración propia.

Se ha registrado también otra realización acústica, dadas las necesidades específicas de los interlocutores en el momento de producirse la comunicación. En el ejemplo siguiente el bajo grado de desconocimiento está dado por la intención del emisor de corroborar una suposición, lo cual se refuerza con el uso del pero.

E: Dayana, ¿ya volviste a llamarlo?

D: Sí, y dice Zulema que hace un siglo que salió de la casa.

3

E: ¿Pero él te dijo que venía? Te lo digo porque a lo mejor ya está en la fiesta y tú aquí esperándolo...

En este caso, la curva de entonación muestra el ascenso típico en el cuerpo del enunciado (véase la figura 6). La variación fundamental ocurre en el tonema, en el que el ascenso es poco pronunciado, al igual que el descenso final. 


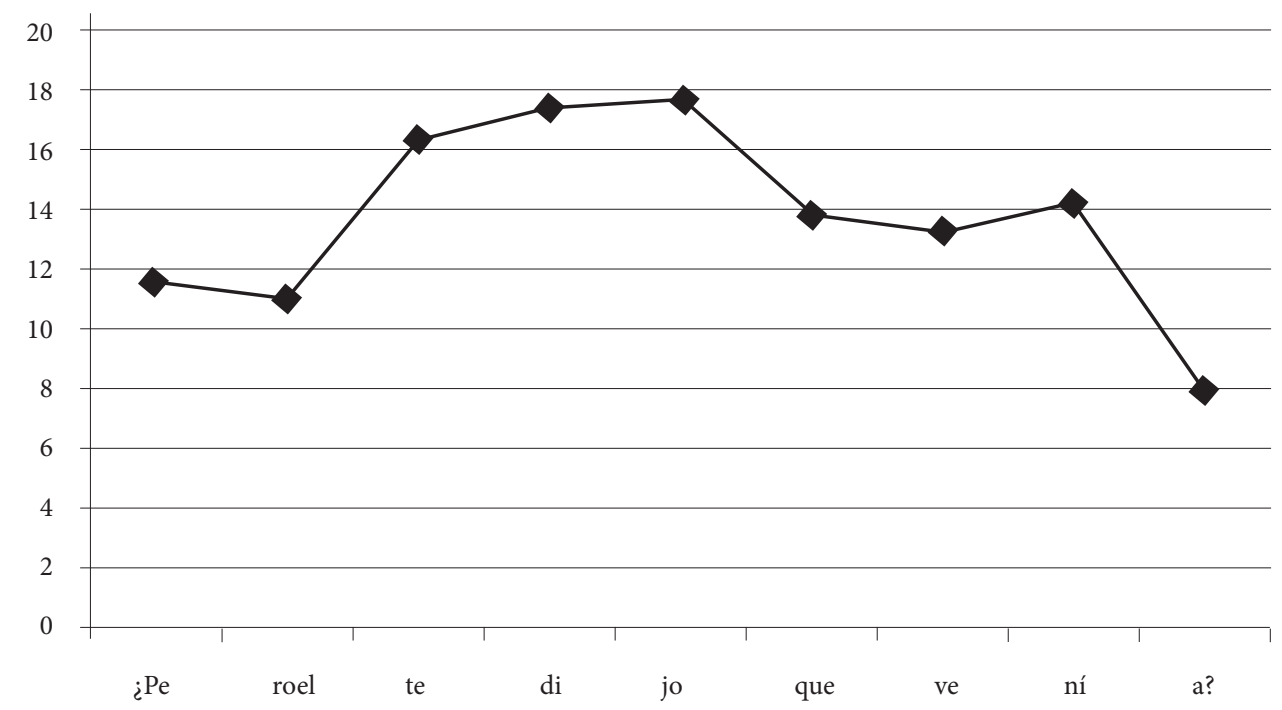

Figura 6. Recorrido de la F0 (st) del enunciado ¿Pero él te dijo que venía? Fuente. Elaboración propia

\section{Interrogativa con matiz de prohibición}

En la muestra se encontró un enunciado interrogativo absoluto que funciona dentro de la secuencia discursiva como un acto de prohibición. ${ }^{16}$ Véase el ejemplo:

B: Alfredo, estuve pensando que me voy a coger un diez.

\section{3}

F: ¿Tú estás loco papi? ¡Si todas las niñas están súper contentas contigo!

Este enunciado se caracteriza por una atenuación en la fuerza impositiva, dada la interacción de la estruc- tura sintáctica con un E3. El contexto temático permite deslindar esta función de la interrogativa, que conserva la forma típica de los enunciados inquisitivos, pero que en la secuencia discursiva evidencia un bajo grado de desconocimiento del emisor, así como su intención de estimular una actitud (en este caso el enunciado tiene el valor de No quiero que hagas $X$ ) en el interlocutor.

Interviene en la elección de este tipo de AHI la relación establecida entre los interlocutores. El tipo de compromiso entre ellos, instaurado solo por medios verbales, impide a Alfredo (F) utilizar otro tipo de enunciado, es decir, una frase con un verbo imperativo, en interacción con un entonema característico: en la variante cubana del español la más frecuente es el E1, propio de enunciados de conclusión.

B: Tú no sabes las ganas que tengo de que seas tú quien esté allí conmigo.

D: Ya tendré la oportunidad cuando te recuperes.

B: ¿Tú me prometes que siempre vas a ser mi nena?

A: Siempre mi amor.

16 Este AHI es un tipo de mandato, cuya fórmula realizativa es Yo intento que tú hagas $X$ acción, en una situación en la que el hablante siente la necesidad de que el oyente realice una acción y actúa para lograrlo. Véase La imperatividad en el español: una aproximación a su estudio, de García
Rodríguez. Según esta autora existen los siguientes tipos de mandato: órdenes y prohibiciones, peticiones, sugerencias, advertencias y amenazas y ruegos. 


\section{Interrogativa con valor de ruego}

También como un AHI perteneciente al mandato, encontramos en la muestra un enunciado cuyo contex- to temático induce su interpretación como un acto de ruego o petición. ${ }^{17} \mathrm{El} \mathrm{AHI}$ tiene lugar en un contexto discursivo que favorece este sentido, dadas las intenciones comunicativas del emisor. Veamos:

B: Tú no sabes las ganas que tengo de que seas tú quien esté allí conmigo.

D: Ya tendré la oportunidad cuando te recuperes.

B: ¿Tú me prometes que siempre vas a ser mi nena?

A: Siempre mi amor.

Situación comunicativa: Yunior (B) conversa con Dayana (D) sobre lo molesto que está comenzando a ser tener relaciones tan asiduamente con extranjeras por dinero. No obstante, extraña su vida de pareja con la muchacha que en verdad quiere. En ese contexto, la interrogación deviene una petición de comprensión y compañía. Sin embargo, es la gestualidad (la mirada sobre todo), la que permite comprender verdaderamente el sentido del enunciado (Véase la figura 7). Yunior agacha un poco la cabeza, frunce el seño y baja los párpados, en señal de ruego.

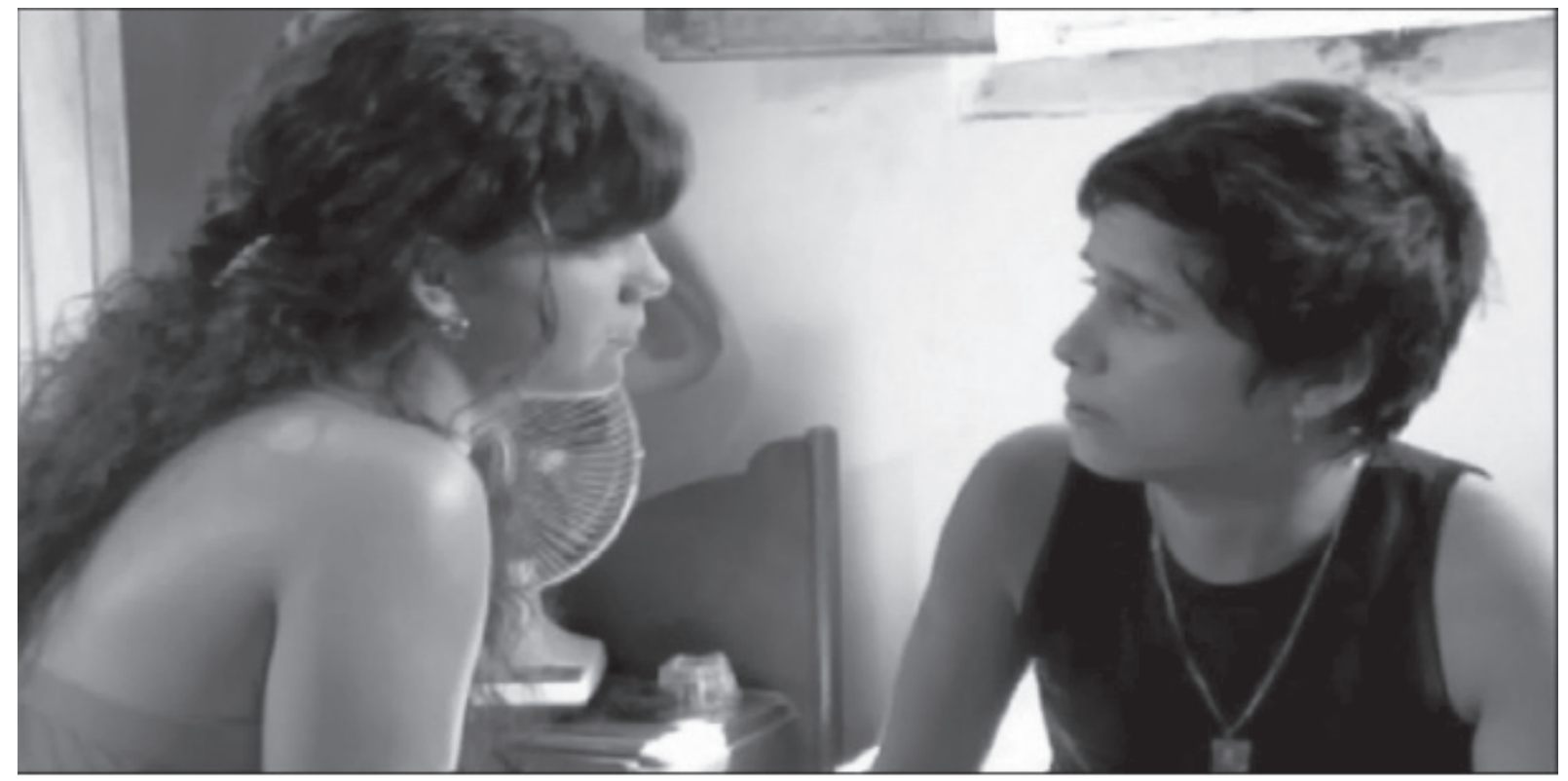

Figura 7. Fotograma que muestra la gestualidad que acompaña el enunciado ¿Tú me prometes que siempre vas a ser mi nena? Fuente. Teleplay "En la otra acera”, 2010.

\section{Interrogativa como acto indirecto de invitación u ofrecimiento}

Se ha registrado igualmente en nuestra muestra una de las funciones que cumple el enunciado interrogativo absoluto en el coloquio, a saber, el acto indirecto de invitación u ofrecimiento. Las estructuras sintácticas interactúan con un E3. Este tipo de enunciados, a la vez que pretende despejar una incógnita (en estos ca-

17 Distingue a este acto de habla una menor intensidad en el modo de persuasión y que el beneficiado con el mandato es el hablante. Según la caracterización de García Rodríguez entre los rasgos distintivos del mandato está el carácter explícito del beneficiario de la realización de la acción. Cuando el beneficiario es el hablante, se trata de ruegos y exhortaciones; cuando es el oyente, se deslindan las sugerencias. 
sos requiere respuesta de sí o no), sirve al emisor de pretexto para convidar. La diferencia fundamental entre estos enunciados y los típicamente inquisitivos es que su contenido proposicional hace referencia a una acción futura que se encuentra bajo el control del des- tinatario y beneficia de algún modo al emisor (Escandell). En el segundo de los ejemplos, la interrogación se incluye dentro de un trato de cortesía (es equivalente a le sirvo un café).

B: ¿Qué tú haces con esa carretilla?

$\mathrm{H}$ : A ver si consigo un menudito para el domingo, que es el cumpleaños de la pura. ${ }^{18}$

3

¿No quieres venir?

B: No puedo brother.

A: Quiero hablar contigo.

D: Claro, siéntese, ¿quiere un poquito de café?

\section{Conclusiones}

El análisis de la muestra audiovisual mostró que, en contraste con lo expresado en las gramáticas al uso, en el español de Cuba no tiene lugar el cambio en el orden de la estructura sintáctica con respecto a los enunciados aseverativos, es decir, se conserva el orden lineal (que ha sido denominado como marcado por las gramáticas tradicionales). Habría que decir que -según muestran nuestros resultados, que deben corroborarse en estudios más profundos-en la variante cubana el orden svo es el no marcado.

Por otra parte, las estructuras sintácticas típicas de la interrogación absoluta, a saber, las que carecen de pronombre o adverbio interrogativo suelen interactuar con el entonema 3 (E3) y con la variante de entonema 3b (VE3b), como ya se había descrito para la isla. Sin embargo, se comprobó que no existe una relación excluyente, lineal, al encontrarse un margen de variación de los patrones entonativos para situaciones comunicativas semejantes, lo que demuestra que estamos ante un sistema dinámico complejo. El AHI que se realiza mediante el E3 puede tener diversas funciones semántico-pragmáticas, todas deducidas en el discurso del contexto lingüístico o discursivo en que se inserta, prueba del abanico de posibilidades que ofrece el sistema de la lengua a los hablantes ante la necesidad de expresar sus intenciones en las más diversas situaciones comunicativas. Así, se deslindaron interrogativas inquisitivas o neutras, e interroga-

18 En el registro popular de la variante cubana del español, esta palabra significa "madre". tivas con valor de enunciación, reproche, corroboración, prohibición, ruego y ofrecimiento o invitación.

Abordar el objeto de estudio desde una perspectiva discursiva parece ser la vía idónea para comprender el hecho lingüístico "interrogación”. Debe partirse, desde luego, de lo que es relativamente estable en el sistema, pero "en algunos casos, el sentido emerge de procesos de semiosis, procesos interaccionales, de los diferentes niveles sistémicos" (García, Losada y Pardo 339).

Queda demostrado que una valoración sobre el uso de las estructuras sintácticas y los contornos melódicos relacionados con ellas debe tener en cuenta el proceso comunicativo en el que se emiten los enunciados, pues el acto de hablar involucra tanto información como acción (Tomlin et al.). Se impone entonces un estudio semántico que no solo estime el contenido proposicional y su relación con la estructura formal del enunciado, sino que sopese en su justa medida las condicionantes pragmáticas de la enunciación.

Por otra parte, el estudio de la estructura sintáctica de los enunciados interrogativos absolutos y su relación con la prosodia es un tema en el que se debe seguir profundizando, dada la carencia de abordajes integrales en el mundo hispánico. Nuestro trabajo solo ha dado los pasos introductorios a búsquedas que deben ser más exhaustivas, si se pretende dar cuenta del sistema de la lengua española, en cualquiera de sus variantes. Partiendo de la limitación que implica haber conformado el corpus a partir de un audiovisual, se impone un análisis de muestras auténticamente provenientes de la conversación, pues solo allí puede estudiarse el fenómeno que nos ha ocupado en toda su complejidad discursiva. 


\section{Referencias}

Austin, John Langshaw. Cómo hacer cosas con palabras: palabras y acciones. Barcelona: Paidós, 1982. Impreso.

Bello, Andrés. Gramática castellana destinada al uso de los americanos. Caracas: Ministerio de Educación, 1951. Impreso.

Bermúdez Sánchez, Madeleyne. La interrogación en el discurso académico oral: un estudio prosódico y semántico-pragmático. Tesis. Universidad de La Habana, 2006. Impreso.

Bosque, Ignacio y Demonte, Violeta, Eds. Gramática descriptiva de la lengua española, RAE, Colección Nebrija y Espasa. Madrid: Universidad Nacional de Educación a Distancia, 1999. Impreso.

Dijk, Teun Adrianus Van. Texto y contexto. Semántica y pragmática del discurso. Madrid: Ediciones Cátedra, S.A, 1980. Impreso.

. Comp. El discurso como estructura y proceso. Barcelona: Editorial Gedisa, 2000. Impreso.

Escandell Vidal, María Victoria. "Los enunciados interrogativos. Aspectos semánticos y pragmáticos.” Gramática descriptiva de la lengua española. Eds. Violeta Demonte e Ignacio Bosque. RAE, Colección Nebrija y Espasa. Madrid: Universidad Nacional de Educación a Distancia, 1999, pp. 3931-3986. Impreso.

García Riverón, Raquel. Aspectos de la entonación hispánica. Metodología I. España: Universidad de Extremadura, 1996a. Impreso.

- Aspectos de la entonación hispánica. Análisis acústico de las muestras del español de Cuba II. España: Universidad de Extremadura, 1996b. Impreso.

. Aspectos de la entonación hispánica. Las funciones de la entonación en el español de Cuba III. España: Universidad de Extremadura, 1998. Impreso.

. "La actualización de la incógnita en las interrogativas rusas y españolas.” Revista Española de Lingüística, jul-dic. 1985. Impreso.

. La interrogación. La Habana, Cuba: Editorial Científico Técnica, 1987. Impreso.

García, Raquel, Losada, Marcia y Pardo, Alba. "El acto de habla interaccional como unidad para el estudio de la oralidad: una visión desde la complejidad." Oralia, 2008, pp. 333351. Impreso.
García Rodríguez, Guadalupe Reina. La imperatividad en el español: una aproximación a su estudio. Tesis. Universidad de La Habana, 1992. Impreso.

Gili Gaya, Samuel. Curso superior de sintaxis española (4ta. edición). Barcelona: Publicaciones y ediciones Spes, 1961. Impreso.

Hernández Alonso, César. Gramática funcional del español, Madrid: Editorial Gredos, 1998. Impreso.

Lemos Ramírez, Gustavo. Gramática española. Quito: Talleres Gráficos de Educación, 1937. Impreso.

Lenz, Rodolfo. La oración y sus partes (4ta edición). Santiago de Chile: Nacimiento, 1944. Impreso.

Martínez Celdrán, Eugenio. Análisis espectrográfico de los sonidos del habla. Madrid: Editorial Ariel, SA, 2007a. Impreso.

Navarro Tomás, Tomás. Manual de entonación española (2da. edición corregida). New York: Hispanic Institute, 1948. Impreso.

Quilis, Antonio. Curso de fonética y fonología españolas (9na edición revisada y aumentada). Madrid: Instituto Miguel de Cervantes, Consejo Superior de Investigaciones Científicas, 1979. Impreso.

Real Academia Española. Esbozo de una Nueva Gramática de la Lengua Española. Madrid: Espasa-Calpe, SA, 1973. Impreso.

. Nueva Gramática de la Lengua Española. Madrid: Espasa Libros, S.L.U, 2009. Impreso.

Salvá y Pérez, Vicente (n.d.). Gramática de la Lengua Castellana. París: Editorial Garnier. Impreso.

Searle, John. Actos de habla. Madrid: Editorial Cátedra, Colección Teorema, 1994. Impreso.

Sosa, Juan Manuel. La entonación del español. Madrid: Ediciones Cátedra, S.A, 1999. Impreso.

Tomlin, Russell S., Forrest, Linda, Pu, Ming Ming y Hee Kim, Myung. "Semántica del discurso." Dijk, Teun Adrianus, Van, comp. El discurso como estructura y proceso. Barcelona, España: Editorial Gedisa, 2000. Impreso. 